\title{
COMPOSTOS NITROGENADOS EM BEBIDAS DESTILADAS: CACHAÇA E TIQUIRA ${ }^{1}$
}

\author{
Lisânias R. POLASTRO², Lisangela M. BOSO², Luiz G. ANDRADE-SOBRINHO², \\ Benedito S. LIMA-NETO², Douglas W. FRANCO²,
}

\begin{abstract}
RESUMO
Utilizando métodos colorimétricos foram investigadas as presenças de íon amônio, uréia e aminoácidos em 51 amostras de aguardente de cana-de-açúcar (cachaça) e em 9 amostras de aguardente de mandioca (tiquira). Foram semelhantes os teores médios de íon amônio determinados para as aguardentes-de-cana $(0,013 \mathrm{mmoles} / \mathrm{L})$ e de mandioca $(0,010 \mathrm{mmoles} / \mathrm{L})$. As tiquiras apresentaram teores médios de aminoácidos $(0,290 \mathrm{mmoles} / \mathrm{L})$ e uréia $(1,45 \mathrm{mmoles} / \mathrm{L})$ superiores aos da aguardente-de-cana: 0,093mmoles/L e 0,316mmoles/L, respectivamente.
\end{abstract}

Palavras-chave: íon amônio; uréia; aminoácidos; cachaça; tiquira.

\section{SUMMARY}

NITROGEN COMPOUNDS IN DISTILLED BEVERAGES: SUGAR CANE AND CASSAVA SPIRITS. Ammonium ion, urea and amino acids were quantified by using colorimetric methods in 51 samples of sugar cane spirit (cachaça) and 9 samples of cassava spirit (tiquira). The average contents of ammonium ion for sugar cane $(0.013 \mathrm{mmoles} / \mathrm{L})$ and cassava $(0.010 \mathrm{mmoles} /$ L) spirits are similar. Tiquiras present average contents of amino acids $(0.290 \mathrm{mmoles} / \mathrm{L})$ and urea $(1.45 \mathrm{mmoles} / \mathrm{L})$ higher than in sugar cane, which are $0.093 \mathrm{mmoles} / \mathrm{L}$ and $0.316 \mathrm{mmoles} / \mathrm{L}$, respectively.

Keywords: ammonium ion; urea; amino acids; cachaça; tiquira.

\section{1 - INTRODUÇÃO}

A etapa de multiplicação celular das leveduras responsáveis pela fermentação alcoólica no caldo de cana depende da presença de compostos nitrogenados tais como proteínas e ácidos nucléicos, os quais são fundamentais à biossíntese da estrutura celular [2]. $O$ conteúdo inicial de nitrogênio total do mosto e as concentrações relativas de cada um dos constituintes nitrogenados afetam o crescimento das leveduras, a velocidade de fermentação e a formação do produto final $[3,8]$. A concentração de nitrogênio total em mostos é muito variável e dependente da espécie vegetal que se utiliza para a fermentação, da região produtora e das condições do solo [9].

O íon amônio $\left(\mathrm{NH}_{4}^{+}\right)$e os aminoácidos glutamina, ácido glutâmico, ácido aspártico, arginina, asparagina, serina e alanina são excelentes fontes de nitrogênio para a Saccharomyces cerevisiae [6]. Para manter a fermentação alcoólica do caldo de cana em boas condições e

${ }_{1}^{1}$ Recebido para publicação em 10/08/00. Aceito para publicação em 11/04/01.

${ }^{2}$ Instituto de Química de São Carlos, Universidade de São Paulo, C.P. 780, CEP 13560-970, São Carlos, SP, Brasil. E-mail: douglas@iqsc.sc.usp.br.

* A quem a correspondência deve ser enviada. assegurar que a taxa de multiplicação celular permaneça elevada, a concentração ideal de nitrogênio amoniacal, geralmente adicionada na forma de $\left(\mathrm{NH}_{4}\right)_{2} \mathrm{SO}_{4}$, gira em torno de 10 a $35 \mathrm{mmoles} / \mathrm{L}$ [2].

A uréia é uma fonte de nitrogênio para as leveduras, no passado era freqüentemente adicionada à dorna de fermentação [2], porém atualmente sabe-se que não é aconselhável, pois este composto pode reagir com o etanol produzindo carbamato de etila, o qual é considerado carcinogênico [12,21]. Mesmo quando não adicionada, a uréia pode ser produzida durante o processo fermentativo, devido ao metabolismo das leveduras [21].

Os aminoácidos, juntamente com os polissacarídeos, as dextranas, os fenóis e os polifenóis podem participar do processo de formação de precipitados, em bebidas fermentadas e destiladas, denominados flocos [4, $14,16,18,19,20]$. Embora os flocos não sejam prejudiciais à saúde e nem interfiram no aroma e sabor das bebidas, eles as depreciam no seu aspecto visual. Além disto os aminoácidos são também possíveis precursores de carbamato de etila, como por exemplo a arginina cuja degradação pelas leveduras produz ornitina e uréia [12]. Portanto, a presença de aminoácidos é indesejável no produto final.

Os aminoácidos presentes nas aguardentes-de-cana e nas tiquiras são provavelmente provenientes da hidrólise de proteínas e dos aminoácidos presentes na própria matéria-prima [10]. A presença de aminoácidos na canade-açúcar [22], bem como na mandioca [6], são bem conhecidas. A sua presença em destilados pode ser conseqüência de falhas de operação no processo de destilação [15] ou por contaminação do açúcar utilizado na adoçagem da cachaça $[5,17]$.

$\mathrm{Na}$ intenção de contribuir para o conhecimento da química dos destilados brasileiros, apresenta-se aqui os resultados das análises de íon amônio, uréia e aminoácidos presentes em 51 amostras de aguardentes de cana e 9 amostras de tiquiras.

\section{2 - MATERIAIS E MÉTODOS}

Neste trabalho foram analisados destilados de canade-açúcar e de mandioca provenientes de várias regiões do país. Das aguardentes-de-cana, 13 amostras são da região nordeste, 4 amostras são da região sul, 34 amostras são da região Sudeste. As nove amostras de tiquiras (sem marca registrada) são oriundas do Estado do Maranhão. 
Caninhas: Safra de Ouro (SP); Jamel (SP); Chave de Ouro (CE); Velho Barreiro (SP); Pitú (PE); Aguardente 51 (SP); Ypioca Prata (CE); Vila Velha (MG); Cana Verde \& Cia (MG); Ypioca Ouro (CE); Ganyviti (SP); Marquesi (SP); Berro (SP); Cavalinho (SP); Baronesa (MG); Oncinha (SP); Rainha da Lavoura (MG); Azuladinha (AL); Aguardente Pirassununga (SP); VeIha Aroeira (MG); Moribondo (PB); Rainha (PB); Sapupara (CE); Aguardente 21 (SP); Espírito de Minas (MG); Capitão das Gerais (MG); Vale Verde (MG); Milagre de Minas (MG); Lua Cheia (MG); Lua Nova (MG); Salinas (MG); São Francisco (RJ); Alambari (PR); Brasileira (SP); Nêga Fulo (RJ); Massaió (AL); Setembrina (RS); Herr Blumenau (SC); Mangueira (PI); Moenda de Ouro (PB); Catedral (SP); Colonial (CE); Trinca 3 (CE); Coqueiro (RJ); Jequity (SP); SR (RJ); Pimpas (SC); Beija Flor (PI); Tridestilado de Cana (SP); Tridestilado Natural (SP) e Corisco (RJ).

Todos os reagentes utilizados nas análises foram de grau analítico (Merck ou Aldrich). A água destilada empregada no preparo de todas as soluções foi tratada por sistema de deionização (Milli-Q).

Nas determinações dos compostos nitrogenados (íon amônio, uréia e aminoácidos) foi utilizado um espectrofotômetro UV-VIS Hitachi, modelo U. 3501.

A determinação de íon amônio foi realizada utilizando a metodologia proposta por WEATHERBURN [23]. Esta é baseada na reação entre fenol e hipoclorito em meio alcalino e na presença de nitroprussiato de sódio. As leituras de absorbância foram efetuadas a $625 \mathrm{~nm}$.

A análise de uréia seguiu o procedimento descrito por DOUGLAS e BREMNER [7]. Este método envolve a medida da absorbância a $527 \mathrm{~nm}$ do produto da reação entre a uréia, diacetil-monoxima e tiocemicarbazida em meio ácido. Com a finalidade de eliminar a interferência do açúcar, as amostras foram inicialmente percoladas por uma resina DOWEX 50WX (200-400mesh), na forma ácida.

A análise dos aminoácidos foi realizada de forma indireta através da diferença entre a concentração de "nitrogênio amínico" e a soma das concentrações do íon amônio e uréia. A determinação de "nitrogênio amínico" foi realizada empregando-se ninidrina [11] e efetuando-se as leituras de absorbância a 570nm.

As curvas de calibração para as soluções padrão dos compostos analisados foram realizadas seguindo os mesmos procedimentos empregados na análise das amostras. Os coeficientes de correlação da reta ( $r$ ) calculados para uréia, íon amônio e aminoácidos a partir dos gráficos (Absorbância vs Concentração) foram respectivamente 0,998; 0,999 e 0,995.

As análises das amostras foram realizadas em duplicatas e os valores reportados representam as médias aritméticas dos resultados obtidos.

\section{3 - RESULTADOS E DISCUSSÃO}

Os resultados das determinações dos compostos nitrogenados (uréia, íon amônio e aminoácidos) pre- sentes nas aguardentes de cana e nas tiquiras estão apresentados nas Tabelas 1 e 2. Na Tabela 3 estão apresentados os valores médios, máximos e mínimos de concentração dos compostos nitrogenados.

TABELA 1. Valores de concentração (mmoles/L) de uréia, íon amônio e aminoácidos em aguardentes de cana.

\begin{tabular}{|c|c|c|c|}
\hline Aguardentes ${ }^{\mathrm{a}}$ & $\mathbf{N H}_{4}{ }^{+}$ & Uréia & Aminoácidos \\
\hline 01 & 0,012 & 0,083 & 0,013 \\
\hline 02 & 0,013 & 0,511 & 0,040 \\
\hline 03 & 0,014 & 0,147 & 0,070 \\
\hline 04 & 0,012 & 0,090 & 0,224 \\
\hline 05 & 0,013 & 0,275 & 0,006 \\
\hline 06 & 0,013 & 0,052 & 0,265 \\
\hline 07 & 0,013 & 0,070 & 0,044 \\
\hline 08 & 0,013 & 0,830 & 0,037 \\
\hline 09 & 0,014 & 0,010 & 0,054 \\
\hline 10 & 0,014 & 0,040 & 0,165 \\
\hline 11 & 0,014 & 0,220 & 0,063 \\
\hline 12 & 0,002 & 0,300 & 0,032 \\
\hline 13 & 0,013 & 0,954 & 0,027 \\
\hline 14 & 0,012 & 0,130 & 0,067 \\
\hline 15 & 0,014 & 0,078 & 0,010 \\
\hline 16 & 0,015 & 0,142 & 0,384 \\
\hline 17 & 0,015 & 0,070 & 0,064 \\
\hline 18 & 0,014 & 0,318 & 0,011 \\
\hline 19 & 0,014 & 0,151 & 0,009 \\
\hline 20 & 0,016 & 0,003 & 0,079 \\
\hline 21 & 0,015 & 0,023 & 0,052 \\
\hline 22 & 0,016 & 0,040 & 0,067 \\
\hline 23 & 0,013 & 0,040 & 0,104 \\
\hline 24 & 0,013 & 0,137 & 0,050 \\
\hline 25 & 0,036 & 0,031 & 0,090 \\
\hline 26 & 0,015 & 0,040 & 0,008 \\
\hline 27 & 0,015 & 0,102 & 0,085 \\
\hline 28 & 0,015 & 0,040 & 0,162 \\
\hline 29 & 0,013 & 0,061 & 0,214 \\
\hline 30 & 0,014 & 0,050 & 0,165 \\
\hline 31 & 0,015 & 0,155 & 0,117 \\
\hline 32 & 0,014 & 0,140 & 0,071 \\
\hline 33 & 0,014 & 0,040 & 0,024 \\
\hline 34 & 0,007 & 0,950 & 0,070 \\
\hline 35 & 0,017 & 0,753 & 0,037 \\
\hline 36 & 0,003 & 0,326 & 0,170 \\
\hline 37 & ND & 1,220 & 0,061 \\
\hline 38 & 0,003 & 0,540 & 0,110 \\
\hline 39 & 0,018 & 0,560 & 0,108 \\
\hline 40 & ND & 0,672 & 0,089 \\
\hline 41 & 0,005 & 0,300 & 0,033 \\
\hline 42 & ND & 0,960 & 0,175 \\
\hline 43 & ND & 0,683 & 0,049 \\
\hline 44 & 0,007 & 0,920 & 0,098 \\
\hline 45 & 0,014 & 0,500 & 0,041 \\
\hline 46 & 0,001 & 0,123 & 0,115 \\
\hline 47 & 0,001 & 0,960 & 0,060 \\
\hline 48 & ND & 0,725 & 0,100 \\
\hline 49 & 0,014 & 0,022 & 0,173 \\
\hline 50 & 0,013 & 0,042 & 0,308 \\
\hline 51 & ND & 0,470 & 0,054 \\
\hline Média & 0,013 & 0,316 & 0,093 \\
\hline
\end{tabular}

$\mathbf{a}=$ Propositalmente a numeração das amostras não obedece a sua ordem de apresentaçao na parte experimental. ND = Concentração inferior a 0,001 mmoles $/ \mathrm{L}$.

Embora seja uma metodologia simples e acessível a qualquer Laboratório, a determinação de "nitrogênio amínico" apresenta limitações. Isto porque alguns com- 
postos nitrogenados, como por exemplo a prolina, não pode ser analisada [13]. Na realidade os valores de "nitrogênio amínico" obtidos pelo método utilizado são estimados e indicam o "valor mínimo", o que atende aos objetivos deste trabalho.

TABELA 2. Valores de concentração (mmoles/L) de uréia, íon amônio e aminoácidos em tiquira.

\begin{tabular}{cccc}
\hline Tiquiras & $\mathbf{N H}_{4}{ }^{+}$ & Uréia & Aminoácidos \\
\hline $\mathbf{0 1}$ & 0,015 & 2,52 & 0,008 \\
$\mathbf{0 2}$ & 0,013 & 1,42 & 0,175 \\
$\mathbf{0 3}$ & 0,014 & 1,42 & 0,514 \\
$\mathbf{0 4}$ & 0,015 & 1,42 & 0,117 \\
$\mathbf{0 5}$ & 0,006 & 1,42 & 0,233 \\
$\mathbf{0 6}$ & 0,004 & 1,67 & 0,387 \\
$\mathbf{0 7}$ & 0,004 & 2,07 & 0,131 \\
$\mathbf{0 8}$ & 0,001 & 0,920 & 0,579 \\
$\mathbf{0 9}$ & 0,014 & 0,146 & 0,470 \\
\hline Média & $\mathbf{0 , 0 1 0}$ & $\mathbf{1 , 4 4 7}$ & $\mathbf{0 , 2 9 0}$ \\
\hline
\end{tabular}

TABELA 3. Valores médios, máximos e mínimos da concentração (mmoles/L) dos compostos nitrogenados encontrados nas aguardentes de cana-de-açúcar e nas tiquiras.

\begin{tabular}{lcccccc}
\hline & \multicolumn{2}{c}{$\mathbf{N H}_{\mathbf{4}}{ }^{+}$} & \multicolumn{2}{c}{ Uréia } & \multicolumn{2}{c}{ Aminoácidos } \\
\cline { 2 - 7 } & Aguardente & Tiquira & Aguardente & Tiquira & Aguardente & Tiquira \\
\cline { 2 - 7 } Média & 0,013 & 0,010 & 0,316 & 1,447 & 0,093 & 0,290 \\
Máximo & 0,036 & 0,015 & 1,220 & 2,525 & 0,384 & 0,579 \\
Mínimo & $\mathrm{ND}$ & 0,001 & 0,003 & 0,146 & 0,006 & 0,008
\end{tabular}

Comparando-se os valores de concentração média de íon amônio presentes nas aguardentes de cana e nas tiquiras (Figura 1), não se observou diferença significativa entre os teores médios deste íon nos destilados.

Relacionando-se a distribuição dos teores médios de íon amônio presentes nos destilados das diversas Regiões, observa-se que as aguardentes de cana da região Sudeste foram as que apresentaram os maiores valores médios de concentração $(0,162 \mathrm{mmoles} / \mathrm{L})$, seguida pelas da região Nordeste com $0,012 \mathrm{mmoles} / \mathrm{L}$. As amostras da região Sul exibem os menores valores médios: 0,001 mmoles/L. Estas diferenças entre as regiões produtoras, talvez possam refletir variações nos teores de sulfato de amônia comumente adicionado [13].

Os dados obtidos na determinação da uréia (Figura 1), revelam que as tiquiras apresentam teores médios de uréia bem superiores $(1,447 \mathrm{mmoles} / \mathrm{L})$ aos das aguardentes de cana $(0,316 \mathrm{mmoles} / \mathrm{L})$. A uréia não é adicionada no processo de fabricação da tiquira. Também não é reportada a presença de uréia como tal na mandioca. Assim, é possível que a mesma se forme durante o processo de fermentação. Estes resultados são preocupantes e provavelmente expliquem os elevados teores de carbamato de etila encontrados na tiquira [1], pois como se sabe este composto pode ser formado a partir da uréia.

Relacionando-se a distribuição do teor médio de uréia pelas distintas regiões produtoras, observa-se que as aguardentes de cana da região Sudeste, Nordeste e
Sul com concentrações médias de 0,244mmoles/L, $0,348 \mathrm{mmoles} / \mathrm{L}$ e $0,913 \mathrm{mmoles} / \mathrm{L}$, respectivamente, apresentam ordem inversa daquela observada para o caso da distribuição do íon amônio por região produtora [13].

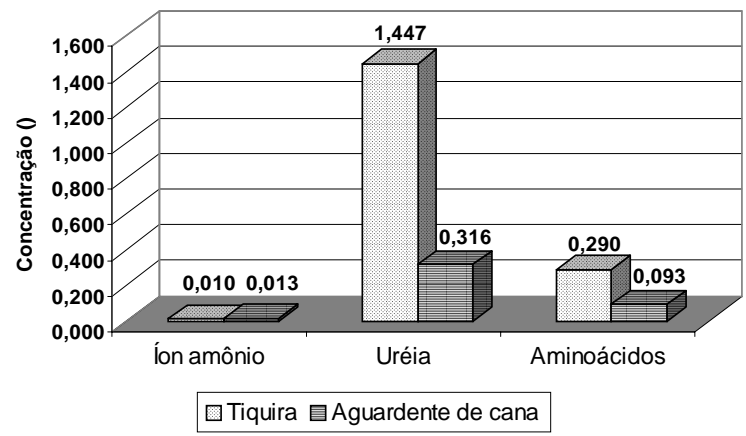

FIGURA 1. Concentração média de íon amônio, uréia e aminoácidos em aguardentes de cana e tiquiras.

Finalmente relacionando-se a distribuição das concentrações médias de aminoácidos pelas regiões produtoras, observa-se que as aguardentes de cana da região Sudeste, Nordeste e Sul apresentaram concentrações médias semelhantes: 0,095mmoles/L, 0,091mmoles/L e $0,077 \mathrm{mmoles} / \mathrm{L}$, respectivamente [13]. Já as tiquiras apresentaram concentrações médias de aminoácidos, superiores às das aguardentes de cana.

Como os aminoácidos e a uréia não são voláteis nas condições em que a destilação da aguardente é efetuada, a sua presença nos destilados só pode ser explicada por arraste ou por contaminação do produto após a sua produção. Como a obtenção da tiquira é basicamente artesanal e submetida a um controle técnico inferior ao da cachaça, deve-se esperar que a contaminação durante a destilação da tiquira seja superior. Assim, um controle mais eficaz do processo de destilação, poderá reduzir ou mesmo eliminar a presença de uréia e aminoácidos nos destilados.

\section{4 - CONCLUSÕES}

- Foi possível identificar e quantificar íon amônio, uréia e aminoácidos nas amostras de aguardente de cana e de tiquira. Os resultados obtidos indicam que as tiquiras apresentam concentrações médias de uréia e aminoácidos superiores aos das aguardentes de cana, ao passo que os teores médios de íon amônio são equivalentes nas duas bebidas.

- A presença indesejável desses compostos nos destilados é provavelmente devida à falhas relacionadas ao processo de destilação. As variações dos teores de uréia e íon amônio em função das regiões produtoras, podem ao menos em parte, serem explicadas em função da não padronização da adição das fontes de nitrogênio ao mosto.

\section{5 - REFERÊNCIAS BIBLIOGRÁFICAS}

[1] ANDRADE, L. G. S. Determinação de cobre, aldeídos, álcoois, acetato de etila, ácidos carboxílicos e carbamato de etila em tiquira (aguardente de mandioca) produzida no 
Estado do Maranhão. São Luís, 1999, 101p., Dissertação (Mestre em Química Analítica) - Universidade Federal do Maranhão (UFMA).

[2] ANGELIS, D. F. Agentes Físicos, Químicos e Microbiológicos que Afetam a Fermentação Etanólica. In: MUTTON, M. J. R. (Ed.) Aguardente de Cana - Produção e Qualidade. Jaboticabal: FUNEP, 1992. p. 49-66.

[3] BELL, A. A.; OUGH, C. S.; KLIEWER, W. M. Effects on must and wine composition, rates fermentation, and wine quality of nitrogen fertilization of Vitis vinifera var. Thompson seedles grapevine. American Journal of Enology and Viticulture, v. 30, n. 2, p. 124-129, 1979.

[4] BOOTH, M.; SHAW, W. ; MORHALO, L. Blending and Bottling. In.: PIGGOT, J. R.; SHARP, R.; DUNCAN, R. E. B. (Ed.). The Science and Technology of whiskies. Essex: LONGMAN SCIENTIFIC \& TECHNICAL, 1989, p. 295326

[5] BOSO, L. M. Determinação de aminoácidos em flocos, açúcares e aguardentes de cana. Relatório FAPESP - bolsa MS (proc. 98/09053-8). Instituto de Química de São Carlos (IQSC-USP).

[6] CIACCO, C. F.; D‘APPOLONIA, B. L. Baking studies with cassava and yam flour. I Biochemical composition of cassava and yam flour. Cereal chemistry, v. $55, \mathrm{n} 3$, p. $402-$ 411, 1988.

[7] DOUGLAS, L. A.; BREMNER, J. M. Colorimetric determination of microgram quantities of urea. Analytical Letters, v. 3, n. 2, p. 79-87, 1970

[8] DUTRA, S. V.; DAUDT, C. E.; SOUZA, M. Aminoácidos livres e uréia durante a fermentação de mosto de Chardonnay com diferentes leveduras. Ciênc. Tecnol. Aliment., v. 19, n. 2, p. 179-182, 1999.

[9] HENSCHKE, P. A.; OUGH, C. S. Urea accumulation in fermenting grapes juice. American Journal of Enology Viticulture, v. 42, n. 4, p. 317-321, 1991.

[10] LIMA, U. A. AGUARDENTES. In: AQUARONE, E.; LIMA, U. A. \& BORZANI, W. (Coord.). Alimentos e Bebidas Produzidos por Fermentação. São Paulo: Edgard Blucher, 1983. Cap. 4, p. 79-103. (Biotecnologia, v.5).

[11] NIVARD, R. J. F.; TESSER, G. I. General Chemistry of the Amino Acids. In: FLORKIN, M.; STOTZ, E, H. (Ed.) Comprehensive Biochemistry. Amsterdam: Elsevier Publ. Co., 1965. Cap. IV, p. 199-200. (v. 6)

[12] OUGH, C. S.; CROWELL, E. A.; MOONEY, L. A. Formation of ethyl carbamate precursors during grape juice urea and ammonia: effects of fortification on intracellular (Chardonnay) fermentation. Addition of aminoacids, and extracellular precursors. American Journal of Enology and Viticulture, v. 39, n. 3, p. 243-249, 1988.

[13] POLASTRO, L. R. Análise de íons metálicos, amônio, uréia e aminoácidos em aguardente. São Carlos, 1999, 55p., Dissertação (Mestre em Química Analítica) - Instituto de Química da São Carlos (IQSC -USP).

[14] REFSGAARD, H. H. F.; SCHAUMBURG, K.; SKIBSTED, L. $\mathrm{H}$. Solid-state ${ }^{13} \mathrm{C}$ NMR investigations of insoluble deposits in aromatic bitters. Zeitschrift fuer LebensmittelUntersuchung und Forschung, v.203, p. 287-292, 1996.

[15] RIFFKIN, H. L.; WILSON, R.; BRINGHURST, T. A. The possible involvement of $\mathrm{Cu}^{+2}$ peptide/protein complexes in the formation of ethyl carbamate. Journal of the Institute Brewing, v. 95, p. 121-122, 1999.

[16] RODRIGUES, M. G. F. Dextranas em açúcares e aguardentes: sua determinação e participação na formação de flocos. São Carlos, 2000, 73p., Dissertação (Mestre em Química Analítica) - Instituto de Química de São Carlos (IQSC-USP).

[17] ROSA, R. D. Las dextranas: su efecto sobre la polarización de la sacarosa y la economía azucarera. International Sugar Journal, v. 100, p. 103-106, 1998.

[18] SIEBERT, K. J. Effects of protein-polyphenol interactions on beverage haze, stabilization and analysis. Journal Agriculture and Food Chemistry, v. 47, n. 2, p.353-362, 1999.

[19] SIEBERT, K. J.; CARRASCO, A.; LYNN, P. Y. Formation of protein-polyfenol haze in beverages. Journal Agriculture and Food Chemistry, v. 44, n. 8, p.1997-2005, 1996.

[20] SIEBERT, K. J.; TROUKHANOVA, N. V.; LYNN, P. Y. Nature of polyphenol-protein interactions. Journal Agriculture and Food Chemistry, v. 44, n. 1, p.80-85, 1996.

[21] STEVENS, D. F.; OUGH, C. S. Ethyl carbamate formation: reaction of urea and citrulline with ethanol in wine under low to normal temperature conditions. American Journal of Enology and Viticulture, v. 44, n. 1, 1993.

[22] THAI, D.X.; TRAN,V. V.; TRAN,T.S.; NGO, S. K.; NGUYEN, U.V. Protein and amino acid composition in a high-lysine, high-threonine-tolerant sugar-cane cell line. Canadian Journal of Plant Science, v. 69, n. 2, p. 625-629, 1989.

[23] WEATHERBURN, M. W. Phenol-hipoclorit reaction for determination of ammonia. Analytical Chemistry, v. 39, n. 8, p. 971-974, 1967.

\section{6 - AGRADECIMENTOS}

Os autores agradecem à FAPESP, pela bolsa MS (proc. 98/09053-8), CAPES e CNPq pelo suporte financeiro. 